\title{
Full-scale Fire Experiment on a Typical Passenger Train
}

\author{
NATHAN WHITE, VINCE DOWLING, and JONATHAN BARNETT \\ CSIRO Fire Science and Technology Laboratory \\ CSIRO Manufacturing and Infrastructure Technology \\ PO Box 56 \\ Highett, Victoria 3190, Australia
}

\begin{abstract}
A full-scale fire experiment has been conducted on a typical Australian passenger train. In this experiment a train fire was allowed to become fully developed involving all combustible materials within the train. This paper focuses on the results of the fully developed fire. The experiment was conducted outside rather than in a tunnel. Measurements included temperatures, vent flows, heat flux and gas analysis. Observations were recorded. It was found that ceiling and upper wall linings are more critical for fire spread than seats and lower wall linings. The ignition source consisted of $1 \mathrm{~kg}$ of crumpled newspaper, the equivalent of a Saturday Melbourne newspaper, located on the floor, beneath a seat in one corner of the carriage interior. The fully developed fire went to flashover $140 \mathrm{~s}$ after ignition and spread inside the vehicle very rapidly, spreading to have involved all fitted materials by $175 \mathrm{~s}$. This highlighted the very short evacuation time available for such an event. From $150 \mathrm{~s}$ large plumes of flame flowed out the side doors and a very high production of smoke was observed. After flashover the peak heat release rate was ventilation controlled. From this it is concluded that many common methods of estimating train fire heat release rate are not valid and that further research into ventilation of train fires is required. This experiment provides unique full scale data for a flashover fire on a furnished suburban rail carriage.
\end{abstract}

KEYWORDS: train fires, fire size, full-scale fire experiments

\section{INTRODUCTION}

Realistic prediction of rail vehicle design fires based on material flammability properties and basic design features of the vehicle is critical to safe design of rail and surrounding infrastructure. However, the current level of knowledge of fire spread and growth within rail vehicles means non-validated assumptions of fire size are made [1,2].

A full-scale fire experiment has been conducted on a suburban passenger carriage to increase understanding of fire growth inside saloons. The objectives of the experiment were to:

- Develop an understanding of how a large fire develops and spreads in a typical rail passenger vehicle.

- Increase understanding of the link between material flammability properties and total fire size.

Previous experiments have been conducted [3-6] on rail passenger vehicles. However, none of these have been on fully developed or flashover fires in complete suburban rail carriages. 
In addition to the fully developed experiment, nine ignition experiments were conducted in one furnished corner of the carriage. The fire size resulting from a variety of types of ignition sources of different severity was investigated. The mechanisms of fire growth from a localised ignition source fire to a large, fully developed fire was also investigated. It was found that, for the materials tested, the behaviour of ceiling and upper wall linings is more important than that of the seats and lower wall linings in predicting the occurrence of fire spread and time to untenable conditions. The results of these tests are intended to be the focus of a separate paper.

This series of experiments was conducted in the open without the interaction that the tunnel would present and specifically focused on the link between materials, vehicle design and fire growth and fire size.

\section{CARRIAGE AND MATERIALS}

The carriage and materials tested were selected from scrap stock. The combination of materials tested was not representative of any particular vehicle in use. Rather it was intended as representative of a typical Australian suburban rail passenger vehicle. The carriage consisted of a stainless steel shell. It was approximately $23 \mathrm{~m}$ long having two doorways on either side and a doorway at either end. It was fitted with plywood flooring, insulated wiring and glass fibre insulation behind aluminium and plywood surfaces in the floor, walls and ceiling throughout. All other materials and fittings had been stripped, including drive train, air conditioners and doors. The carriage had some penetrations through the floor, walls and ceiling that were patched for the experiments.

Materials and fittings installed in the carriage to represent a typical configuration are listed in Table 1.

Table 1. Installed materials.

\begin{tabular}{|l|l|}
\hline \multicolumn{1}{|c|}{$\begin{array}{c}\text { Carriage } \\
\text { component }\end{array}$} & \multicolumn{1}{c|}{ Material description } \\
\hline $\begin{array}{l}\text { Floor and lower wall } \\
\text { coverings }\end{array}$ & $\begin{array}{l}\text { Carpet (5mm thick nylon loop pile with a 3mm thick jute } \\
\text { backing) }\end{array}$ \\
\hline $\begin{array}{l}\text { Window surround, } \\
\text { end wall and } \\
\text { vestibule wall } \\
\text { linings }\end{array}$ & $\begin{array}{l}\text { Gel-coated glass reinforced polyester (GRP) panels 3-5 mm } \\
\text { thick }\end{array}$ \\
\hline Ceiling linings & Gel-coated glass reinforced polyester panels 3-5 mm thick \\
\hline Seating & $\begin{array}{l}\text { Fabric lined polyurethane foam. Mainly on steel frames. A } \\
\text { limited number of GRP frames. }\end{array}$ \\
\hline Windows & $\begin{array}{l}\text { Aluminium-framed. The top openable panels were constructed } \\
\text { of single layers of hardened 5 mm Armourfloat glass. The } \\
\text { fixed bottom panels were double glazed. The outer layer was } \\
\text { 6.5 mm Neutrex laminated glass with a medium neutral brown } \\
\text { tint. The inner layer was a single layer of hardened 6 mm } \\
\text { Armourfloat glass }\end{array}$ \\
\hline
\end{tabular}

Due to limited availability, materials listed in Table 1 were only fitted to the first $10 \mathrm{~m}$ along the vehicle from the north end. The remaining window openings were sealed with gypsum plasterboard to maintain similar ventilation conditions as for a fully glazed car. 
Both end doorways and the two doorways on the east side were sealed with $10 \mathrm{~mm}$ gypsum plasterboard. Both doorways on the west side were left open, representing a scenario where the train had stopped at a platform and the passengers had disembarked. Other items such as the plywood floor and concealed wiring and insulation blanket extended through the full carriage. The materials listed in Table 1 were also used in nine corner ignition experiments and were tested in the cone calorimeter.

\section{EXPERIMENTAL PROCEDURE}

The ignition source for the fully developed fire was $1 \mathrm{~kg}$ of crumpled newspaper piled on the floor in a corner behind the end seat shell. This equates to one Saturday newspaper in Melbourne. The newspaper was ignited using a gas flame. The resulting train fire was left to burn until most of the available fuel had been consumed and the fire had decayed. Fire fighters suppressed remaining smouldering materials and made the test area safe.

Data was logged throughout the experiment at five second intervals. An important aspect of this series of experiments was the observations of the fire development and its effects. Four digital video cameras were positioned at various locations outside and within the carriage. A thermal imaging camera was used to observe hot layer development. Digital still photos were taken of all significant events. Particular points of observation included the rate of fire growth, fire spread and maximum fire size, changes in ventilation, changing tenability, quantity of smoke produced, and the volume of flame leaving open vents.

\section{INSTRUMENTATION}

No facilities suitable for conducting full scale oxygen consumption calorimetry were available for these experiments. Instead the following measurements were taken to indicate fire growth.

\section{Temperature Measurement}

Gas temperatures and spread of flame within the carriage were monitored using Type K MIMS thermocouples. Eleven thermocouple trees were located along the centre of the carriage at $2 \mathrm{~m}$ spacings. Thermocouple trees at both open side doors measured outflowing gas and flame temperatures. Two thermocouples on the outside of each window monitored the time of window glazing failure. Two windows near the ignition area were more fully instrumented with thermocouples to provide information relating to the conditions for failure of the glazing and out-flowing gas temperatures once the glazing failed.

\section{Flow Measurement}

Bi-directional pressure probes connected to differential pressure transducers were used to measure the flow of gases at the openings. It was hoped that flow measurements in conjunction with temperature measurements and observation would provide a means for estimating the rate of heat energy leaving the carriage through the openings. There were four pressure probes at various heights in one side doorway and three pressure probes at various heights outside the window opposite the ignition point. 


\section{Heat Flux Measurement}

Medtherm water-cooled heat flux meters with a range of $0-100 \mathrm{~kW} / \mathrm{m}^{2}$ were used to measure the total heat flux from the fire at different points. For the fully developed fire, three heat flux meters were placed at floor level directed towards the ceiling, located at both ends between the carriage end wall and vestibule and in the centre between both vestibules. These were to provide data relating to the development of the hot layer and flashover conditions along the carriage. A fourth heat flux meter was placed outside the carriage at a distance of $6 \mathrm{~m}$ from the side door closest to the ignition seat, facing the side door. This was to measure the heat flux from flames exiting the door.

\section{Gas Analysis}

A portable $\mathrm{O}_{2}, \mathrm{CO}$ and $\mathrm{CO}_{2}$ gas analyser was used. Gas was continuously sampled from a point located at a height of $1.9 \mathrm{~m}$ above floor level between the ignition end of the carriage and the vestibule.

\section{RESULTS AND OBSERVATIONS}

Following ignition, the fire grew rapidly, with flames impinging on the ceiling at $20 \mathrm{~s}$. Prior to flashover, there was only limited involvement of the seat in the area exposed to the ignition fire. The fire continued to grow on the GRP wall linings in the corner, and on the ceiling linings. Flames spread laterally along the ceiling with increased smoke production until at $140 \mathrm{~s}$ it was judged that flashover had occurred at the ignition end of the carriage. At this point, materials, such as carpets and seats, below the already burning ceiling at the ignition end ignited, and the fire proceeded to rapidly spread along the vehicle to involve all fitted materials. At $140 \mathrm{~s}$ the floor heat flux meter closest to the ignition point had reached $20 \mathrm{~kW} / \mathrm{m}^{2}$ and low height thermocouple temperatures rapidly increased. Thus the conventional criteria for flashover were met within the local ignition area. Figure 1 shows the temperatures at the centre of the carriage $2 \mathrm{~m}$ from the ignition location.

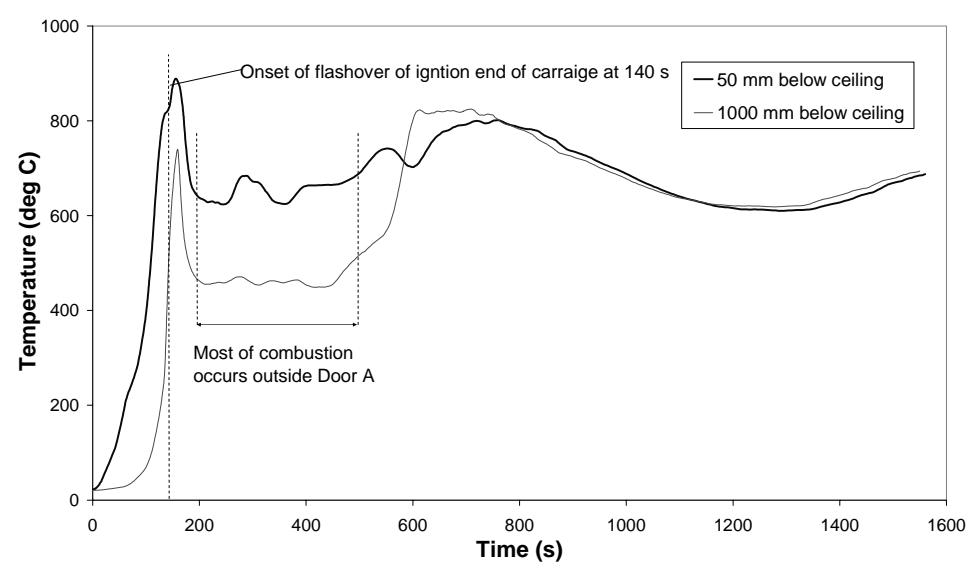

Fig. 1. Temperatures at centre of carriage $2 \mathrm{~m}$ from ignition point. 
Beyond $600 \mathrm{~s}$ the temperatures in Fig. 1 converge. This is most likely due to molten material falling on the thermocouples or the thermocouple trees collapsing. Similarly located thermocouples on other trees did not converge in this manner.

Fig. 2 shows the time to involvement of materials at thermocouple tree positions along the carriage as determined by low height temperatures exceeding $400^{\circ} \mathrm{C}$.

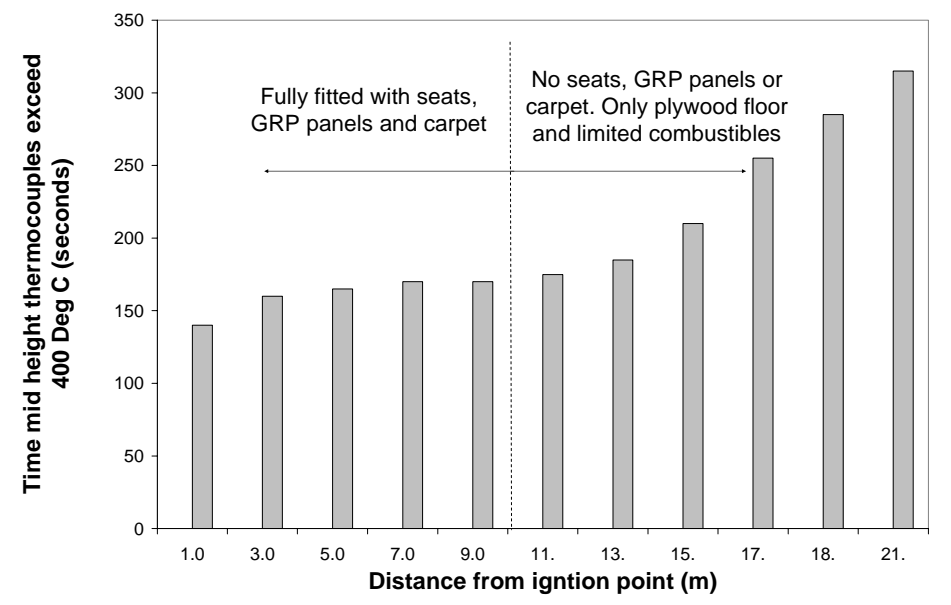

Fig. 2. Time to involvement of materials at discrete distances along the carriage.

Following flashover at the ignition end at $140 \mathrm{~s}$, the fire spread to fully involve materials at the end of the fitted area, $10 \mathrm{~m}$ from the ignition point, at $175 \mathrm{~s}$. This corresponded to a measured heat flux of $20 \mathrm{~kW} / \mathrm{m}^{2}$ at floor level in the centre of the carriage length at $175 \mathrm{~s}$. Spread of fire extending more than $15 \mathrm{~m}$ from the ignition point was slower due to the limited combustible available to support spread. However, aluminium panels eventually melted, exposing fibreglass insulation and insulated wires, which ignited. The plywood floor ignited, extending to the furthest side door (18 $\mathrm{m}$ from ignition point). Beyond this, the plywood did not ignite.

Flames rolled along the ceiling and out the passenger door furthest from the ignition area, and would have ignited the GRP ceiling panels, if they had been present for the full length. Also, the temperatures at the ceiling at the opposite end of the carriage exceeded $600{ }^{\circ} \mathrm{C}$ (Fig. 3, and 4). It is evident that if the vehicle had been fitted with materials for the entire carriage length, then all materials would have become involved. At $270 \mathrm{~s}$ a loud crash occurred within the carriage. This is likely to have been ceiling panels falling to the floor as the supports burnt out. 


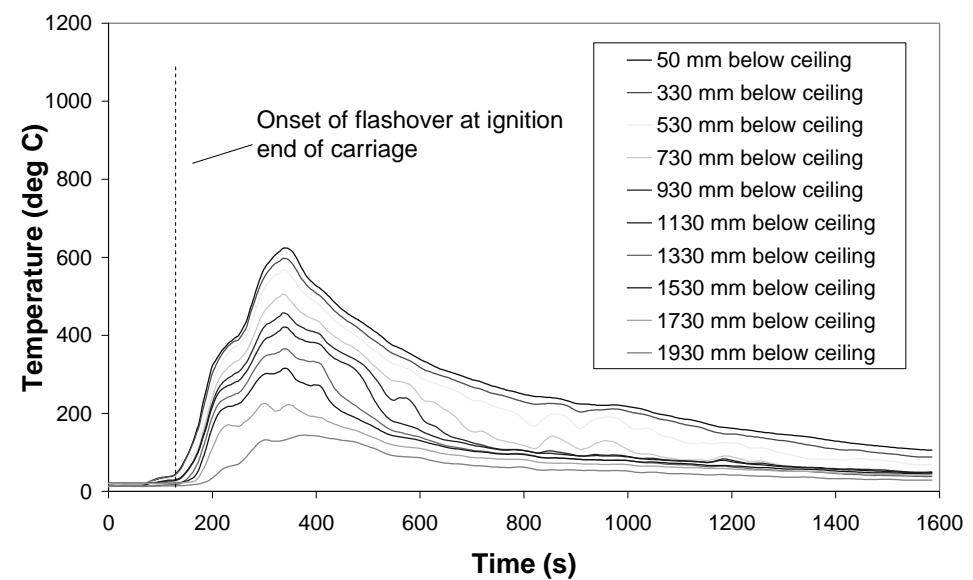

Fig. 3. All temperatures at centre of carriage at opposite end from ignition point.

Whilst there were eleven thermocouples on each thermocouple tree (see Fig. 3), for clarity only high, intermediate and low height temperatures have been presented in other figures.

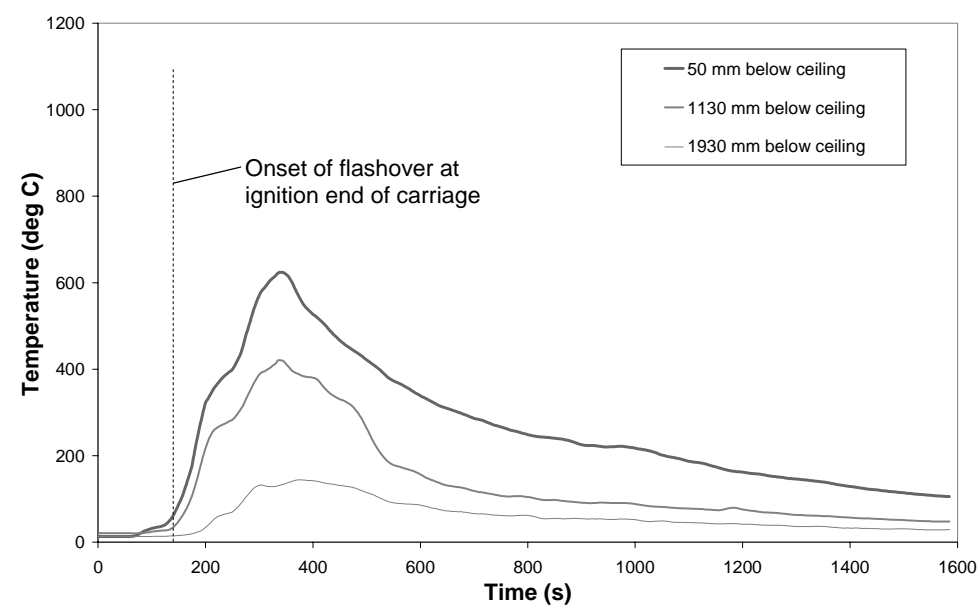

Fig. 4. Some temperatures on centreline at end away from ignition point.

At the onset of flashover at $140 \mathrm{~s}$, the smoke layer dropped, providing no visibility within the carriage and untenable conditions rapidly developed, as shown in Fig. 5. 


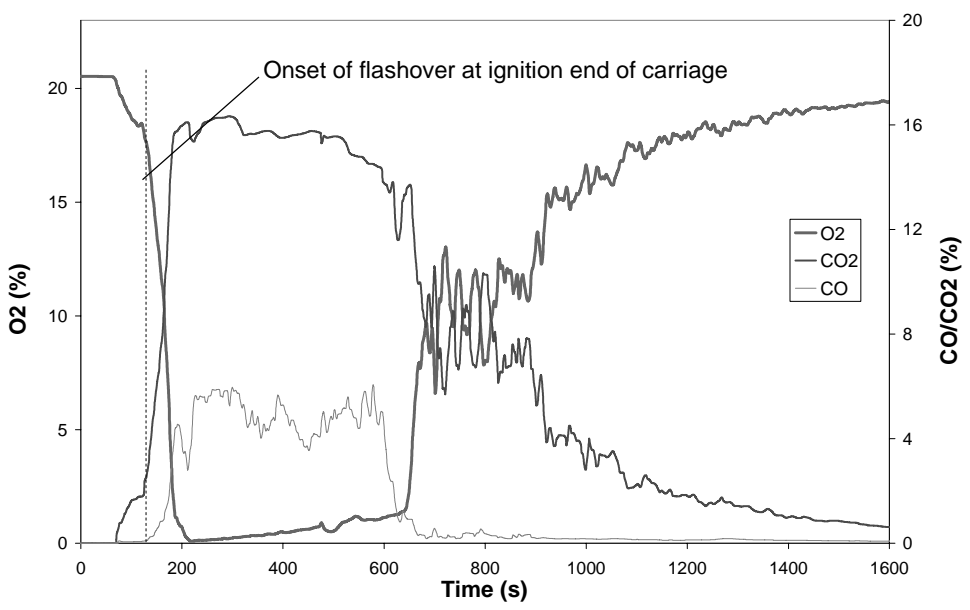

Fig. 5. Gas concentrations at head height within carriage.

After the onset of flashover, during the fire peak from $150 \mathrm{~s}$ to $400 \mathrm{~s}$, the majority of the combustion appeared to be occurring external to the vehicle in the flame plume exiting the open door closest to the ignition area. This may explain the drop in interior temperatures during this period (Fig. 1). This flame plume exhibited cyclic turbulent pulsing, and at its peak had a height of approximately $5 \mathrm{~m}$ (extending $3 \mathrm{~m}$ above the roof of the vehicle), and a width of approximately $2.5 \mathrm{~m}$ (Fig. 6).

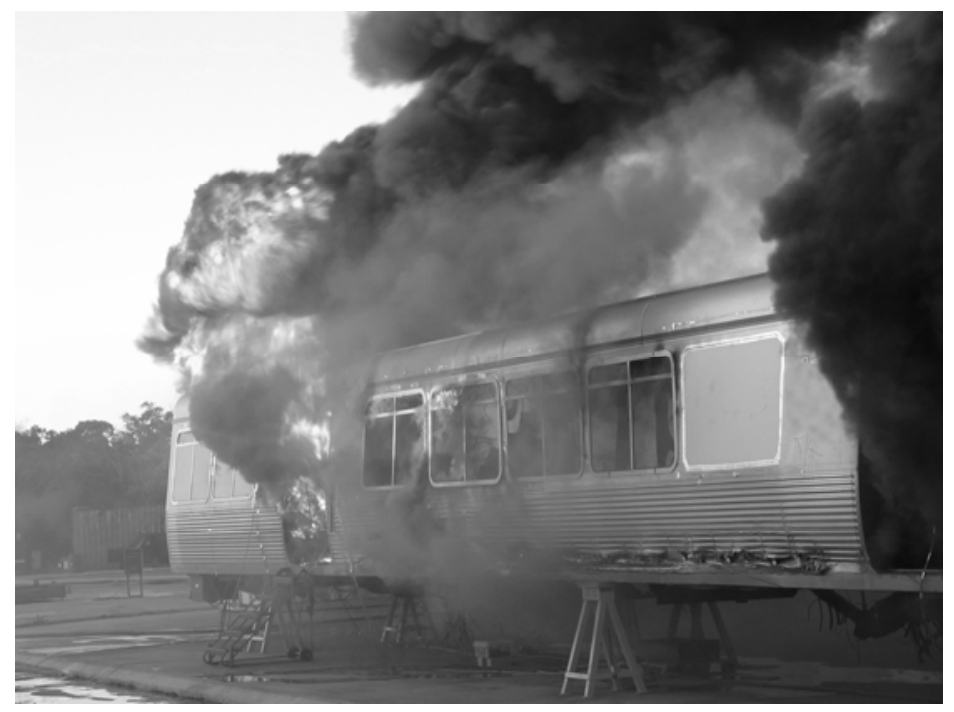

Fig. 6. Fire plume out door closes to ignition point at 3 minutes.

Flames also travelled along inside the carriage, and flowed out the passenger door at the opposite end of the vehicle from $270 \mathrm{~s}$ to $370 \mathrm{~s}$. A high rate of smoke production was observed during the fire peak, as shown in Fig. 7. 


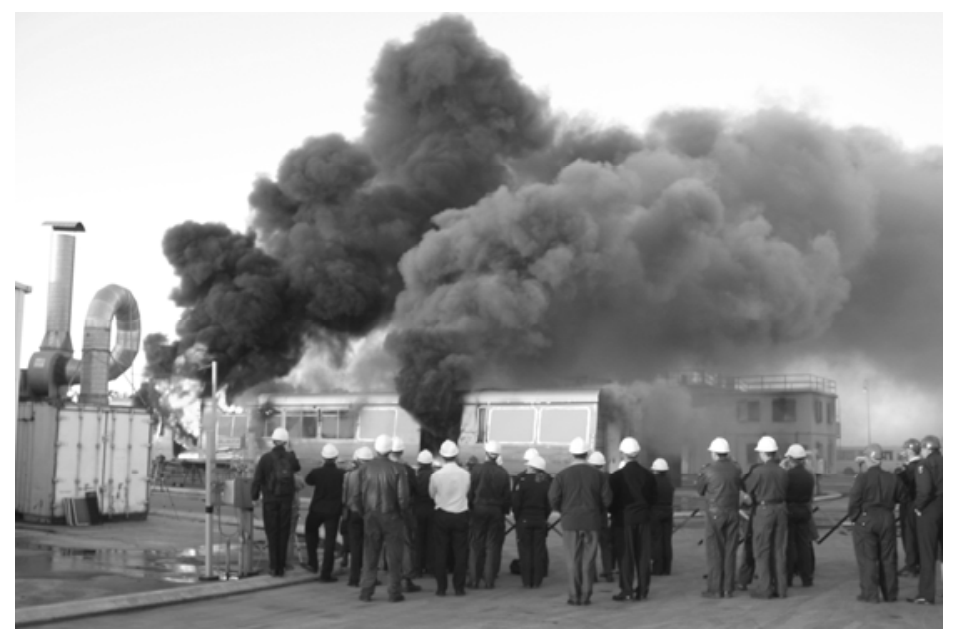

Fig. 7. Smoke production at 3 minutes.

The temperatures at various heights for both passenger doors are shown in Fig. 8 and Fig. 9.

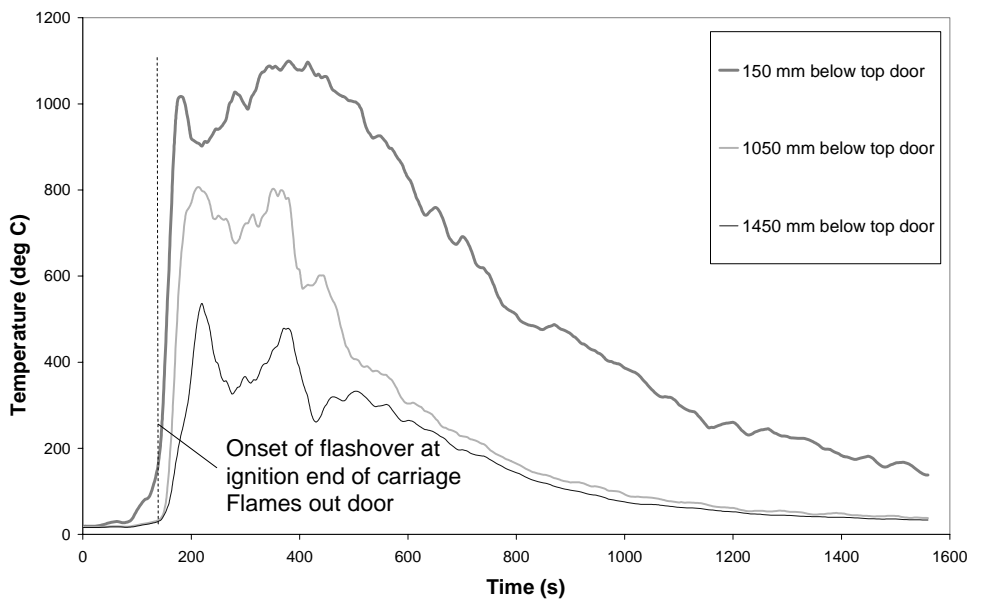

Fig. 8. Some gas temperatures at the open passenger door closest to ignition point. 


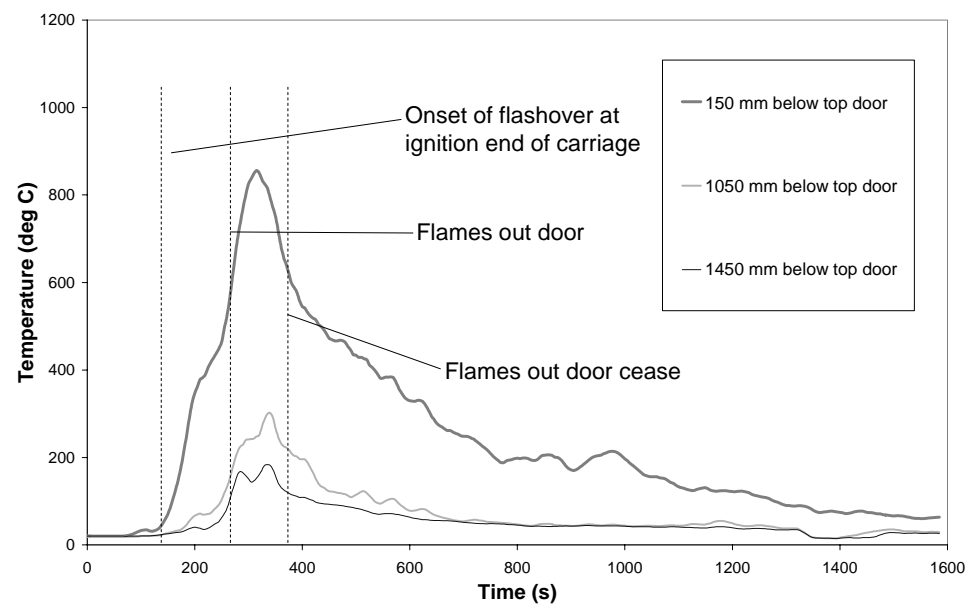

Fig. 9. Gas temperatures at open passenger door furthest from ignition point.

Window glazing maintained integrity, preventing significant increases in fire ventilation throughout the peak of the fire. The upper openable panels, which were single layers of toughened glass, began to fail at approximately $280 \mathrm{~s}$. However, these represent a much smaller vent area than the lower fixed panels. The lower panels, which were double glazed with laminated and toughened glass, began to fail at $380 \mathrm{~s}$. By the time a significant area of windows had broken, the fire had begun to decay. If windows had broken during the fire peak, this would have resulted in increased HRR. Typical temperature data for a window located next to the side passenger door closest the ignition point is given in Fig. 10.

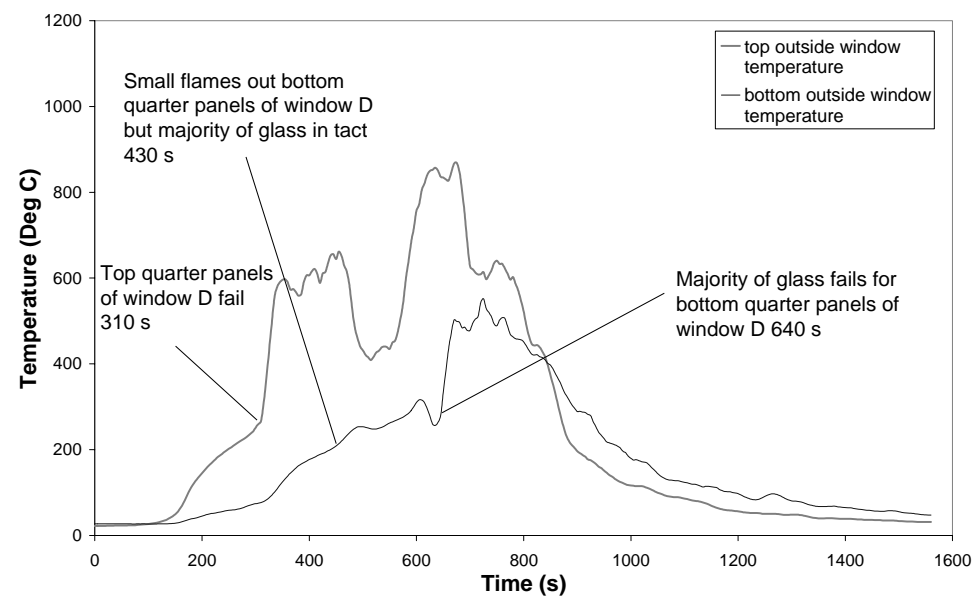

Fig. 10. Some temperatures outside the second window from the ignition point.

As the tests were conducted in the open, the effects of wind on vent flow were significant. This resulted in unsteady flow measurements and introduced difficulties in direct estimation of out flowing heat energy through windows and doors. The large component of combustion occurring exterior to the vehicle also effects estimation of HRR. These factors made it difficult to predict HRR. 
Total heat flux measurements are illustrated in Fig. 11. The heat flux at floor level in the vestibule closest to the ignition point was $20 \mathrm{~kW} / \mathrm{m}^{2}$ at $140 \mathrm{~s}$, and at the centre of the carriage it was $20 \mathrm{~kW} / \mathrm{m}^{2}$ at $175 \mathrm{~s}$. This compares well with the observed times to full involvement at different locations in the vehicle shown in Fig 3.

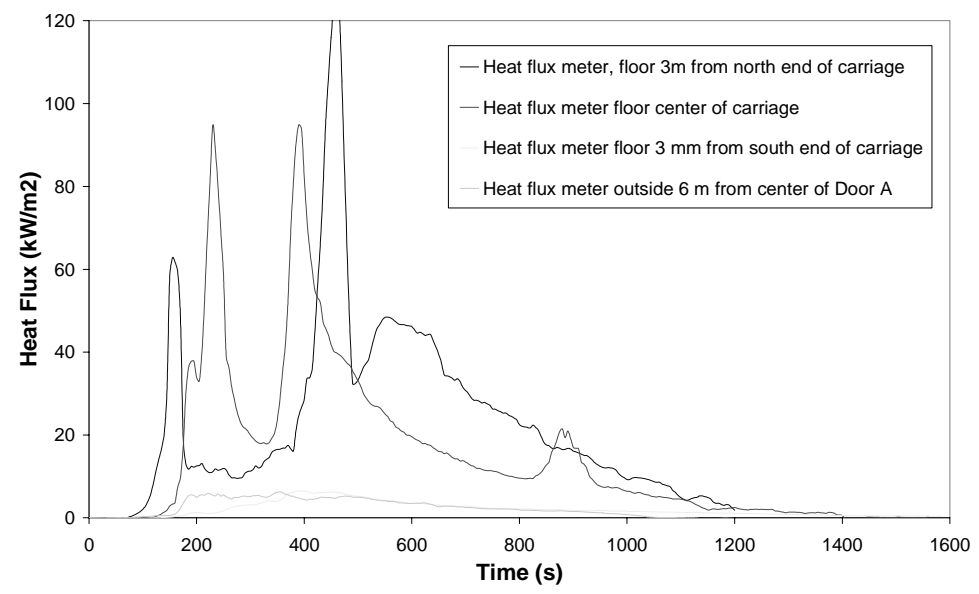

Fig. 11. Total heat flux.

The heat flux at floor level in the centre of the vestibule furthest from the ignition point does not exceed $6.5 \mathrm{~kW} / \mathrm{m}^{2}$. This is mainly radiation from the hot layer, as there was limited combustion at this end of the vehicle (the plywood floor past the door did not ignite). The heat flux external to the vehicle measured at a point $6 \mathrm{~m}$ from the side passenger door closest the ignition location maintained a steady $5-6 \mathrm{~kW} / \mathrm{m}^{2}$ from $190 \mathrm{~s}$ to $350 \mathrm{~s}$ and then steadily decayed. A heat flux of $2.5 \mathrm{~kW} / \mathrm{m}^{2}$ is commonly used as the tenability limit for evacuation in a fire [9]. Exposure to a heat flux of $6 \mathrm{~kW} / \mathrm{m}^{2}$ causes pain in $8 \mathrm{~s}$ and blistering of the skin in $20 \mathrm{~s}$.

\section{DISCUSSION}

For the materials used in this experiment, the behaviour of the ceiling and upper wall linings was more important than that of the seats and lower wall linings in predicting the occurrence of flashover and time to untenable conditions in a typical suburban rail carriage. Prior to flashover, flame spread was firstly on the upper wall linings, and then on the ceiling linings. It is unlikely that fires will spread on seats and lower wall linings alone. It was observed that conditions only become untenable once the fire spread beyond the ignition area and flashover occurred. This indicates that significant increases in fire safety of vehicles may be achieved by improvements to ceiling materials and upper wall linings.

The experiment confirms that, if a large fire develops in a carriage, then flashover will occur. Thus an assumption of a slower progressing fire spread along the carriage is not valid. Once flashover occurred, the fire was observed to become ventilation controlled. Therefore estimation methods that assume rapid involvement of all materials but relate heat release rate to fuel loading without considering ventilation $[7,8]$ are not valid.

A significant finding from these experiments is the short time available for occupants to evacuate if flashover occurs in a vehicle. Flashover occurred at $140 \mathrm{~s}$. This is likely to be 
insufficient time to evacuate a fully occupied carriage, especially if mobility disabled are present. However statistics indicate the occurrence of such a fire on a heavily occupied vehicle is unlikely [11].

Although HRR could not be directly measured for these experiments they are unique in that they have not been conducted with the enhancing effects of a tunnel and that the information derived has focused primarily on the link between materials, carriage design and fire size.

If ventilation is the determining factor in prediction of passenger rail vehicle HRR, then further research needs to be conducted to determine if existing correlations for ventilation controlled HRR are applicable for the unique geometry of a carriage. Reliable prediction of failure of window materials is also required.

Further modelling work is being carried out by CSIRO using the data generated to estimate HRR for this experiment.

\section{CONCLUSIONS}

The behaviour of the ceiling and upper wall linings was found to be more important than that of the seats and lower wall linings in predicting the occurrence of flashover and time to untenable conditions in a typical suburban rail carriage.

If a large fire develops in a carriage, then flashover will occur, and the fire will become ventilation controlled.

There is only about two minutes for occupants to evacuate if flashover occurs in a carriage.

This experiment was unique in that it was not conducted in a tunnel and that it focused on the link between materials, carriage design and fire size.

Further research needs to be conducted to determine if existing correlations for ventilation controlled heat release rates are applicable to the geometry of a carriage. Reliable prediction of failure of window materials is also needed.

\section{ACKNOWLEDGMENTS}

These experiments were conducted in collaboration with a rail operator and Queensland Fire and Rescue Service (QFRS).

\section{REFERENCES}

[1] Dowling, V.P. and White, N., "Fire Sizes in Railway Passenger Saloons," in 6th Asia-Oceania Symposium on Fire Science \& Technology, Daegu, Korea, March 17-20, 2004.

[2] Munro, J., Smith, G., Dowling, V., and White, N., "Combining Design Fires and Risk Assessment to Achieve Tunnel Safety," Proceedings TMI Fourth International Conference - Tunnel Fires, Basel, Switzerland, December 242002.

[3] European Commission, "Firestarr Project Final Report," 2001.

[4] Haack, A., "Fire Protection in Traffic Tunnels: General Aspects and Results of the EUREKA Project,” Tunnel Fire Safety, 13, pp 377-381, 1998. 
[5] Peacock, R.D. and Braun, E., "Fire Tests of Amtrak Passenger Rail Vehicle Interiors," NBS Technical Note 1193, National Bureau of standards, Washington DC, USA, 1984.

[6] Peacock, R.D. et al., "Fire Safety of Passenger Trains; Phase III: Evaluation of Fire Hazard Analysis Using Full-Scale Passenger Rail Car Tests," NISTIR 6563, National Institute of Standards and Technology, USA, 2004.

[7] Duggan, G. J., "Usage of ISO 5660 Data in UK Railway Standards and Fire Safety Cases," in Fire Hazards, Testing, Materials and Products, Proceedings of A One Day Conference, Rapra Technology Ltd, Shawbury, Shrewsbury, Shropshire, UK, Paper 3, March 13, 1997.

[8] Kennedy, W.D., Ray, R.E., and Quinan, J.W., "A Short History of Train Fire Heat Release Calculations," Annual ASHRAE meeting, Toronto, Canada, 1998.

[9] White, N., "Full-Scale Passenger Train Fire Experiment," CSIRO Internal Report Doc CMIT-(C)-2004-442, CSIRO Fire Science and Technology Laboratory, Melbourne, 2005.

[10] Buchanan, A.H., "Fire Engineering Design Guide," Centre for Advanced Engineering, University of Canterbury, New Zealand, 2001.

[11] New South Wales Fire Brigades, "Annual Statistical Report 2001/02 incorporating a Ten Year Review 1989/90 to 1998/99," 2002. 